\title{
Isolation and characterization of a novel paraffin wax-degrading bacterium, Pseudomonas sp strain PW-1, from petroleum-contaminated sites
}

\author{
Y.L. Zhang, Z. Liu, and T. Liu \\ Agricultural College, Heilongjiang Bayi Agricultural University, \\ Daqing, Heilongjiang, China \\ Corresponding author: T. Liu \\ E-mail: liutongamy@sina.com \\ Genet. Mol. Res. 15 (2): gmr.15028021 \\ Received November 6, 2015 \\ Accepted February 19, 2016 \\ Published June 10, 2016 \\ DOI http://dx.doi.org/10.4238/gmr.15028021
}

\begin{abstract}
An isolate capable of degrading paraffin wax was isolated from petroleum-contaminated sites in Daqing, China, and identified as Pseudomonas sp strain PW-1 by analyzing the 16S rDNA sequence (GenBank accession No.: KF529529) as well as the biochemical and physiological characteristics. The optimized degradation conditions of the isolate were as follows: $\mathrm{FeSO}_{4}$ metal ion concentration of 0.01 $\mathrm{g}$, temperature of $30^{\circ} \mathrm{C},\left(\mathrm{NH}_{4}\right)_{2} \mathrm{SO}_{4}$ nitrogen source concentration of $1.5 \mathrm{~g} / \mathrm{L}$, and a carbon: nitrogen ratio of 10:1. Response surface methodology-based analysis of the culture time, inoculation amount, and initial $\mathrm{pH}$ of the medium revealed that the optimal theoretical conditions were a culture time of 11.16 days, inoculation amount of $3.13 \%$, and an initial $\mathrm{pH}$ of 9.29. The theoretical degradation rate was up to $54.68 \%$ under the optimal conditions. Taking into account the experimental conditions of a laboratory, 11.2 days of cultivating time, $3 \%$ inoculum, and a medium initial $\mathrm{pH}$ of 9.3 were used in practical settings. Experimental results showed that the degradation rate of paraffin wax was $52.85 \%$, which demonstrated that this strain could degrade $1050 \mathrm{mg}$ paraffin wax, using it as the sole carbon source, in a
\end{abstract}


1000-mL minimal salts medium. These results indicate that the strain PW1 can be used for application in oil wells with paraffin deposition problems in order to enhance oil recovery.

Key words: Paraffin wax; Pseudomonas sp; Degradation conditions; Response surface methodology; Potential bacteria

\section{INTRODUCTION}

The oil industry is currently facing new levels of competition as non-renewable resources are becoming increasingly exhausted. During the crude oil recovery process, paraffin wax is dissolved in the oil to precipitate crystals. These crystals lead to the formation of paraffin wax deposits because of temperature and pressure reduction, and the escape of light alkanes to the atmosphere (Bott, 1997; Azevedo and Texeira, 2003). Furthermore, the crystals attach to the walls of the oil wells, the casing wall, pump, and other production equipment, which reduces the mobility of oil and blocks the transport in the pipelines (Brown et al., 1993; Leorpz, 2004; Huang et al., 2010). According to reports, more than half of the extractable oil remains underground after the first and second attempts at oil recovery. Therefore, the presence of paraffin wax deposits in oil has become a pressing issue in the oil industry. At present, this problem is solved using thermal fluid treatments, the use of chemicals and solvents, or pigging (scraping) (Burguer et al., 1981; Barker et al., 2001). However, most of these procedures currently have certain disadvantages. For example, mechanical scraping causes loss due to significant downtime in production. Chemicals and solvents, aside from being hazardous (Araújo et al., 2010), only partially dissolve or disperse paraffin, which ends up being deposited elsewhere in the tubing (Khalil et al., 1997). Finally, these remedial options are expensive.

In order to improve crude oil recovery, microbially enhanced oil recovery technology has been adopted by many oil industry companies for recovery from oil reservoirs, mobilization of heavy crude oil in pipelines, and removal of oil sludge from storage facilities. In addition, microbially enhanced oil recovery technology has other outstanding advantages such as high biodegradability, low toxicity, high environmental compatibility, high selectivity, and their ability for specific activity at extreme temperatures, $\mathrm{pH}$, and salinity. Paraffins are mainly composed of long-chain alkanes, which are known to be degraded by microbes. For example, the Pseudomonas aeruginosa strain WatG has the ability to degrade the paraffinic alkanes, hexatriacontane $\left(\mathrm{C}_{36}\right)$ and tetracontane $\left(\mathrm{C}_{40}\right)$, in a minimal salts medium containing crude oil (Hasanuzzaman et al., 2007). Pseudomonas putida GPol (commonly known as Pseudomonas oleovorans GPo1) is among the most extensively studied alkane-degrading bacteria, which catalyzes the hydroxylation of linear and branched aliphatic, alicyclic, and alkylaromatic compounds. This strain is mostly known for its efficient utilization of medium and lengthy carbon chain alkanes from $\mathrm{C}_{12}$ to $\mathrm{C}_{22}$ (van Beilen et al., 2001). Several Acinetobacter strains are known as n-alkane utilizers. Among them, the Acinetobacter sp. strain M-1 has the ability to degrade a variety of n-alkanes, including very long-chain n-alkanes with carbon chain lengths of $\mathrm{C}_{20}$ to $\mathrm{C}_{44}$ at ambient temperature (Tani et al., 2001). In addition, Koma et al. (2001) have also studied an Acinetobacter strain that can assimilate long-chain n-paraffins from the waste oil of car engines. Kotlar et al. (2007) isolated and identified an Acinetobacter sp. 6A2 strain that is capable of degrading alkanes with a chain length ranging from $\mathrm{C}_{10}$ to $\mathrm{C}_{40}$ and a melting 
point of $52^{\circ}-54^{\circ} \mathrm{C}$. Sood and Lal (2008) isolated a Geobacillus kaustophilus TERINSM strain from a soil sample contaminated with paraffinic crude oil that can degrade $600 \mathrm{mg}$ of paraffin wax in $1000 \mathrm{~mL}$ minimal salts medium.

Daqing city has the largest oil fields in China and is an important petrochemical base that contributes about 50 million tons of crude oil each year. However, the production rate is declining and the paraffin in crude oil, which causes deposition and restricts oil flow, is suspected to be the cause. The removal of paraffin wax from oil wells is a serious problem; if solved, the production of crude oil will greatly improve. Therefore, in this study, the investigation was aimed at (1) isolating a strain capable of degrading paraffin wax from Daqing's petroleum-contaminated sites, (2) identifying the isolate by analyzing the 16S rDNA sequence, as well as the biochemical and physiological characteristics of the isolate, and (3) optimizing factors that affect the degradation of paraffin wax. This study shows a strain that effectively removes paraffin wax that causes deposition in oil wells.

\section{MATERIAL AND METHODS}

\section{Collection of soil samples and enrichment culture}

Soil samples were collected from 3 sites of each oil field in Daqing in the Heilongiiang province of China. Each sample was loaded into sterile 250-mL Erlenmeyer flasks. The mouth of the flasks was immediately covered with sterile cotton wool. The samples were shipped to the laboratory in an ice bucket for the isolation of microorganisms. The soil sample $(5 \mathrm{~g})$ was inoculated into $100 \mathrm{~mL}$ minimal salts medium (MSM) in a 250-mL Erlenmeyer flask. The MSM medium contained $1 \mathrm{~g} \mathrm{KH}_{2} \mathrm{PO}_{4}, 0.5 \mathrm{~g} \mathrm{MgSO}_{4}, 0.01 \mathrm{~g} \mathrm{FeSO}_{4}, 1.5 \mathrm{~g} \mathrm{NaNO}_{3}, 0.002$ $\mathrm{g} \mathrm{CaCl}_{2}$, and $1.5 \mathrm{~g} / \mathrm{L}\left(\mathrm{NH}_{4}\right)_{2} \mathrm{SO}_{4}$, supplemented with $0.2 \%(\mathrm{w} / \mathrm{v})$ paraffin wax as the sole carbon source. Inoculation was performed with shaking at $180 \mathrm{rpm}$ at $30^{\circ} \mathrm{C}$. Every 7 days, $2 \mathrm{~mL}$ of the enrichment culture was transferred into $100 \mathrm{~mL}$ fresh MSM. After 7 cycles of enrichment, the bacterial culture was diluted 10,000-fold by adding sterile water, and $100 \mu \mathrm{L}$ of the dilution was then spread onto Luria Bertani broth (LB) plates. A single colony on the plates was isolated and purified further in liquid media with paraffin wax. The purified isolates were kept in $25 \%$ glycerol at $-70^{\circ} \mathrm{C}$.

\section{Screening for isolates degrading paraffin wax}

The purified isolated strains were used to test for paraffin wax degradation. The isolates were cultured for $18 \mathrm{~h}$ in LB media. After culturing, a cell density of $10^{8} \mathrm{CFU} \mathrm{mL}^{-1}$ was obtained and was used to inoculate into the MSM with $1 \%$ paraffin wax as the sole carbon source on a rotary shaker $(180 \mathrm{rpm})$ at $30^{\circ} \mathrm{C}$ for 7 days. Uninoculated bacterial controls were used to monitor the abiotic loss of paraffin wax. The residual undegraded paraffin wax was weighed.

\section{Identification of the paraffin wax-degrading strain}

The isolate was analyzed for morphological, biochemical, and physiological characteristics according to the method proposed by Buehanan and Gibbons (1974). To identify the isolate more accurately, we analyzed partial $16 \mathrm{~S}$ rRNA gene nucleotide sequences corresponding to positions 27-1492 of the Escherichia coli 16S rRNA gene. Genomic 
DNA was obtained following the method described by Ferrara et al. (2006). The universal oligonucleotide primers $27 \mathrm{~F}$ and $1492 \mathrm{R}$ were used to amplify the $16 \mathrm{~S}$ rRNA gene. Polymerase chain reaction (PCR) amplifications were performed with $0.5 \mu \mathrm{L}$ Extensor Hi-Fidelity PCR Enzyme Mix (5 U/L), $5 \mu \mathrm{L} 10$ x buffer, $4 \mu \mathrm{L} \mathrm{MgCl}_{2}(25 \mathrm{mM}), 1 \mu \mathrm{L}$ dNTP $(10 \mathrm{mM}), 0.5 \mu \mathrm{L}$ primer $27 \mathrm{~F}(50 \mu \mathrm{M}), 0.5 \mu \mathrm{L}$ of the primer $1492 \mathrm{R}, 1 \mu \mathrm{L}$ of template DNA (50-100 ng), and $37.5 \mu \mathrm{L} \mathrm{ddH_{2 }}$ O. The PCR conditions were as follows: 1 cycle at $95^{\circ} \mathrm{C}$ for $5 \mathrm{~min}, 30$ cycles at $95^{\circ} \mathrm{C}$ for $1 \mathrm{~min}, 50^{\circ} \mathrm{C}$ for $30 \mathrm{sec}, 72^{\circ} \mathrm{C}$ for $2 \mathrm{~min}$, and a final cycle at $72^{\circ} \mathrm{C}$ for $5 \mathrm{~min}$. The amplification products that were obtained after gel electrophoresis were purified using a QIAamp Mini Kit. The purified product was ligated to the pMD19-T vector, transformed into E. coli $\mathrm{DH} 5 \alpha$, and then sequenced. The obtained 16S rRNA gene nucleotide sequences were compared with known sequences in GenBank using the BLAST program. Sequence alignment was carried out using ClustalX (version 2.0), and the phylogenetic trees were drawn using the software, MEGA version 5, by the neighbor-joining method.

\section{Effect of environment factors on paraffin wax degradation}

The isolate was used to investigate the effects of different parameters on paraffin wax degradation. It was cultured in $250-\mathrm{mL}$ flasks containing $100 \mathrm{~mL} \mathrm{LB}$ medium until the lateexponential phase. Bacterial cells were collected after centrifugation at $5000 \mathrm{rpm}$ for $10 \mathrm{~min}$. The cell pellets were washed twice with sterilized MSM and finally resuspended in MSM. The optical density at $600 \mathrm{~nm}\left(\mathrm{OD}_{600}\right)$ of bacterial cells was adjusted to 0.5 , and used as the inoculum. For all experiments, unless otherwise stated, $1 \%$ inoculums were cultured in 250 $\mathrm{mL}$ flasks containing $100 \mathrm{~mL}$ MSM (pH 7.0), which, in turn, contained $200 \mathrm{mg} / \mathrm{L}$ paraffinwax, at $30^{\circ} \mathrm{C}$ and $180 \mathrm{rpm}$ in a rotary shaker for 7 days. The effect of metal ions $\left(\mathrm{Ca}^{2+}, \mathrm{Mg}^{2+}\right.$, $\mathrm{Cu}^{2+}, \mathrm{Fe}^{3+}$, and $\left.\mathrm{Mn}^{2+}\right)$, incubation temperature $\left(20^{\circ}, 25^{\circ}, 30^{\circ}, 35^{\circ}\right.$, and $\left.40^{\circ} \mathrm{C}\right)$, nitrogen source $\left[\left(\mathrm{NH}_{4}\right)_{2} \mathrm{SO}_{4}, \mathrm{NaNO}_{3}\right.$, and $\left.\mathrm{NaNO}_{2}\right]$, and carbon: nitrogen ratio $(5: 1,10: 1$, and 25:1) on paraffin wax degradation and bacterial growth were investigated. The residual undegraded paraffin wax was extracted by the aforementioned methods. The degradation ratio was calculated using the following formula: the paraffin wax degradation rate $(\%)=\{$ the total paraffin wax $(0.5$ g) - undegraded paraffin wax] / total paraffin wax $\}$ x 100. Bacterial growth was measured at an optical absorbance value of $600 \mathrm{~nm}$. The abiotic loss of paraffin wax was used as control in the culture without inoculums. Each experiment was performed in triplicate. All data were subjected to an analysis of variance (ANOVA) with DPS (Data Processing System) procedures (Zhejiang University, China). The values were statistically analyzed using Duncan's test and presented as the means \pm standard errors $(\mathrm{N}=3$ or 4$)$. Statistically significant differences among the values at $\mathrm{P}<0.05$ are indicated by different letters. The charts were generated using Origin (version 8.0).

\section{Response surface methodology (RSM) experimental design}

One-factor-at-a-time method and RSM were used to select appropriate levels of the culture time $(4,6,8,10$, and 12 days), the inoculation amount $(1,2,3,4$, and $5 \%)$, and the medium initial $\mathrm{pH}(6,7,8,9,10$, and 11). A quadratic regression model describing the effect of the 3 process conditions on the rate of biodegradation was developed using a Box-Behnken experimental design. Considering the culture time, inoculation amount, and medium initial $\mathrm{pH}$ as parameters, as well as the paraffin wax degradation rate as the response value, the 3 
factors and levels were analyzed using a Box-Behnken central composite experimental design. The response surface variables and the optimal conditions for paraffin wax degradation were obtained by the Design-Expert 8.0 software (Stat-Ease, Inc. Minneapolis, MN, USA) based on regression analysis of the experimental data.

\section{RESULTS AND DISCUSSION}

\section{Isolation and identification of strain PW1}

Six isolates from 36 samples of oil-contaminated soil that were collected from 12 different oil fields in Daqing were capable of degrading paraffin wax using it as the sole carbon source (Figure 1). Out of all of the isolates, 1 strain was able to degrade approximately $500 \mathrm{mg} / 1000$ $\mathrm{mL}$ of paraffin wax in culture for 7 days and it is considered to have the most potential for the degradation of paraffin wax. The isolated strain was a gram-negative rod that could use paraffin wax as its sole carbon source. Its biochemical characteristics are shown in $\underline{\mathbf{S 1} \text { Table. Because }}$ of intrinsic limitations, the biochemical and physiological features enabled only a preliminary identification in the study by Huang et al. (2009). Complete identification was confirmed in this study by combining similar results from 16S rDNA sequencing as well as the analysis of biochemical and physiological characteristics. The 1501-bp segment of this strain's 16S rRNA gene was amplified and sequenced. The 16S rDNA sequence was deposited in the NCBI with the accession No. KF529529 and then retrieved from the classifier program, Ribosomal Database Project II. The 16S rRNA sequence showed 100 and $99 \%$ similarity to the complete sequence of the Pseudomonas sp FP1-1 16S rRNA gene (GenBank accession No.: DQ118951.1) and P. citronellolis (GenBank accession No.: AM088478.1), respectively. The relationship of this isolate with closely related members is shown in Figure 2. Phylogenetic analysis indicated that the isolate was closer to Pseudomonas sp and it was probably a species belonging to this genus. However, the results still did not confirm the specific species when analyses were performed for their biochemical and physiological features, and therefore, it was preliminarily identified as a novel Pseudomonas sp strain, named as Pseudomonas sp PW-1.

The occurrence of Pseudomonas strains in a hydrocarbon-contaminated environment has been reported in some studies. Obayori et al. (2008) isolated 3 Pseudomonas species from oil-polluted soils. Yalcin et al. (2011) also found Pseudomonas putida RW-П from petroleum refinery wastewater. Recently, Liu et al. (2011) obtained a Pseudomonas sp BS1 strain from Daqing oil-contaminated sites in China.

\section{Effect of metal ions and temperature on biodegradation of paraffin wax}

Many studies have indicated that several metal ions are toxic to microorganisms and inhibit biodegradation (Moreira et al., 2012). In the present study, the effect of metal ions on the biodegradation of paraffin wax was studied with 5 kinds of metal ions $\left(\mathrm{Fe}^{2+}, \mathrm{Ca}^{2+}\right.$, $\mathrm{Cu}^{2+}, \mathrm{Mg}^{2+}$, and $\mathrm{Mn}^{2+}$ ). Experimental results showed that metal ions had variable effects on the degradation of paraffin wax. The degradation rates were the highest in $\mathrm{FeSO}_{4}(41.17 \%)$, followed by $\mathrm{CaCl}_{2}\left(40.78 \%\right.$ ). The degradation rates in $\mathrm{MnSO}_{4}$ and $\mathrm{MgCl}_{2}$ were markedly lower than that in $\mathrm{Fe}^{2+}$ and $\mathrm{Ca}^{2+}$. The presence of $1 \mathrm{mM} \mathrm{Cu}^{2+}$ was found to strongly inhibit the growth of the strain and to reduce biodegradation, as shown in Figure 3A. It is likely that $\mathrm{Cu}^{2+}$ inhibits the activity of the degradation enzyme. Similar phenomena have been observed in 


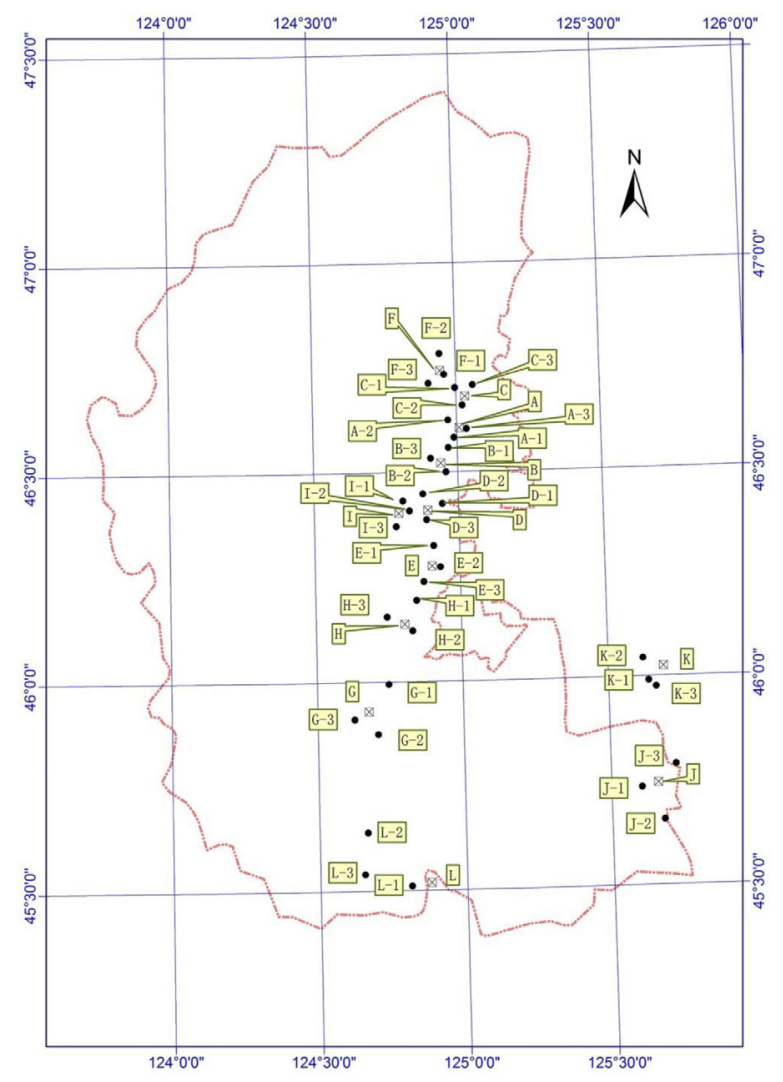

Figure 1. Geographical distribution of sampling sites in Daqing Oil field. A, B, C, D, E, F, G, H, I, J, K, L represent the First, Second, Third, Fourth, Fifth, Sixth, Seventh, Eighth, Ninth, Tenth, Eleventh, Twelfth oil field, respectively. Each oil field includes 3 sampling sites around producing well.
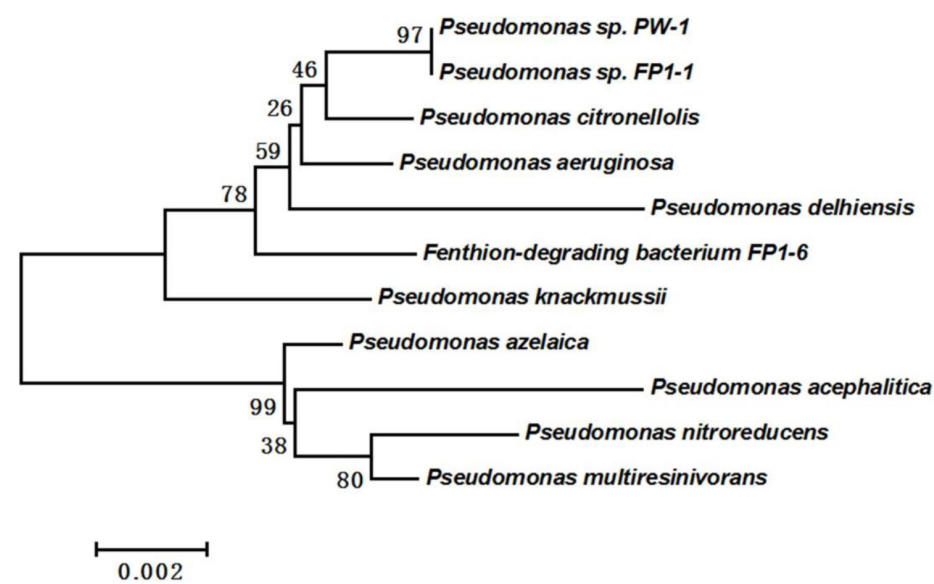

Figure 2. NJ bootstrapping phylogenetic tree of isolate PW-1 and their closest strains on the basis of the 16S rRNA gene sequences. The bar indicates 0.002 substitutions per nucleotide position. 
Labrys portucalensis F11 for fluorobenzene biodegradation (Moreira et al., 2013).

Temperature is a critical parameter affecting biodegradation (Atlas, 1975). The degradation of paraffin wax by Pseudomonas sp. PW-1 occurred over a temperature range of $20^{\circ}$ to $40^{\circ} \mathrm{C}$ (Figure 3B). A maximum degradation of approximately $26.8 \%$ was observed at $30^{\circ} \mathrm{C}$ under experimental conditions, whereas lesser degradation occurred at $20^{\circ} \mathrm{C}$. The results indicated that this strain has the highest enzymatic activities for the degradation of paraffin wax when it was grown at $30^{\circ} \mathrm{C}$.

\section{Effect of nitrogen source and carbon: nitrogen ratio on biodegradation of paraffin wax}

Literature has indicated that nitrogen sources play a key role in the biodegradation of alkanes (Das and Chandran, 2011). To investigate the effect of nitrogen source on paraffin wax degradation, $\left(\mathrm{NH}_{4}\right)_{2} \mathrm{SO}_{4}, \mathrm{NaNO}_{3}$, and $\mathrm{NaNO}_{2}$ nitrogen sources were tested in our study. In the present study, supplementation of $\left(\mathrm{NH}_{4}\right)_{2} \mathrm{SO}_{4}$ as the nitrogen source achieved the highest degradation rate (46.5.1\%), followed by $\mathrm{NaNO}_{3}(32.4 \%)$, and $\mathrm{NaNO}_{2}(24.2 \%)$ (Figure $3 \mathrm{C}$ ). The results suggested the $\left(\mathrm{NH}_{4}\right)_{2} \mathrm{SO}_{4}$ was a good nitrogen source aiding degradation as well as good bacterial growth. Zhuang (2008) reported that $\left(\mathrm{NH}_{4}\right)_{2} \mathrm{SO}_{4}$ was the optimum nitrogen source for diesel degradation using different Pseudomonas species. It is likely that $\mathrm{NH}_{4}^{+}$was used directly by this bacterium, whereas $\mathrm{NO}_{3}{ }^{+}$and $\mathrm{NO}_{2}{ }^{+}$needed transformation by nitrification.

The carbon: nitrogen ratio is one of the most important factors affecting degradation of alkanes. In this study, paraffin wax as the carbon source and $\left(\mathrm{NH}_{4}\right)_{2} \mathrm{SO}_{4}$ as the nitrogen source were studied to achieve optimal degradation conditions. The results showed that the highest degradation rate (37.3\%) occurred at a carbon: nitrogen ratio of 10:1, followed by 5:1 and 25:1 (Figure 3D). Similar results were found by Guerra-Santos et al. (1984).
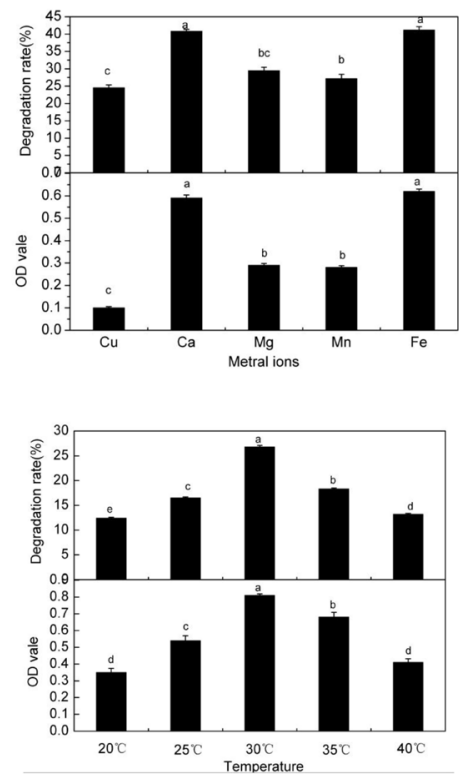

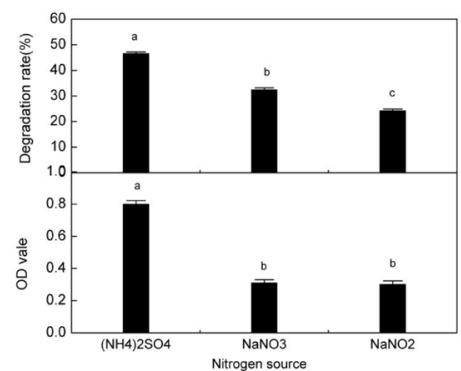

D

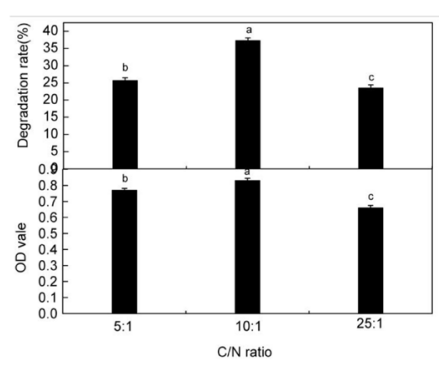

Figure 3. Effect of metal ion (A), temperature (B), nitrogen source $(\mathbf{C})$, and $\mathrm{C} / \mathrm{N}$ ratio $(\mathbf{D})$ on biodegradation of paraffin-wax. Biomass was denoted in terms of OD 600. Degradation rate was calculated by the formula above. 


\section{Experimental results from RSM}

\section{Statistical analysis of the culture time, inoculation amount, and pH using RSM}

On the basis of single-factor results and Box-Behnken central composite experimental design principles, using the culture time, inoculation amount, and medium initial $\mathrm{pH}$ as the parameters, and paraffin biodegradation rate as the response value, a response surface optimization test with 17 experimental points was designed. Three levels were selected for each factor: low level "-1", middle level " 0 ", and high level " +1 ". The code values of the response surface experiments factorial levels and the results of 17 experimental points are shown in $\underline{\mathbf{S 2}}$ and $\underline{\mathbf{S 3} \text { Tables. }}$

The following quadratic regression equation was obtained using the Design-Expert 8.0 statistical software. Y represents degradation rate as the objective function.

$\mathrm{Y}=52.43+5.31 \times \mathrm{A}+3.32 \times \mathrm{B}+3.48 \times \mathrm{C}-0.94 \times \mathrm{A} \times \mathrm{B}+0.58 \times \mathrm{A} \times \mathrm{C}+0.43 \times \mathrm{B}$ $\times \mathrm{C}-4.63 \times \mathrm{A}^{2}-11.37 \times \mathrm{B}^{2}-6.71 \times \mathrm{C}^{2}$

From the results of ANOVA ( $\underline{\mathbf{S 4} \text { Table }})$, it can be seen that the regression model is extremely significant, indicating that the model could correctly predict the relationship between paraffin wax degradation rate and each of the examined factors. The lack of fit proposed in this model, $\mathrm{P}>0.05$ (0.1968), was not significant, which showed that no other factor could significantly influence the experiments. This demonstrates that this regression model fitted well with the actual experiments. The order of various factors affecting the degradation rate of paraffin wax theoretically should be as follows: culture time $>$ medium initial $\mathrm{pH}>$ inoculation amount. Moreover, the correlation coefficient $\mathrm{R}^{2}=0.9245$ showed that this regression model built from the use of the response surface experimental design is efficient, proving that this model was suitable for the theoretical prediction of paraffin wax degradation rate.

\section{Response surface analysis of degradation rate paraffin wax}

Figure 4A shows the effect of culture time and inoculation amount on paraffin wax degradation rate. The slanted surface of inoculums appears steeper than culture time, which indicates that inoculums significantly influence the degradation rate. When the inoculums were close to $3 \%$ in amount and culture time close to 11 days, there was a high degradation rate within a certain range. Figure 4B shows changes that are more intensive occur along the axial $\mathrm{pH}$, which indicates that $\mathrm{pH}$ has more influence on response surface than culture time. When the culture time was around 11 days and the medium initial $\mathrm{pH}$ was between 9.0 and 9.5 , the degradation rate was at its maximum. Figure $4 \mathrm{C}$ shows the effect of inoculums and a medium initial $\mathrm{pH}$ on the degradation rate. When the inoculums were between 3 and $3.5 \%$ in amount, and the medium initial $\mathrm{pH}$ was between 9.0 and 9.5, the best degradation results were observed.

\section{Determination of optimal conditions}

Using the equation for ridge top analysis of regression, the optimal theoretical conditions suggested were that the cultivating time is 11.16 days, inoculation amount is $3.13 \%$, and the medium initial $\mathrm{pH}$ is 9.29. Under these optimal conditions, the theoretical degradation rate increases to $54.68 \%$. Considering the experimental conditions of the laboratory, 11.2 days 
of culture time, $3 \%$ inoculums, and a medium initial $\mathrm{pH}$ of 9.3 were used in the practical test. The results showed that the degradation rate of paraffin wax was $52.85 \%$, reaching a degradation of $1050 \mathrm{mg} / \mathrm{L}$ of paraffin, which is in agreement with the values of the theoretical prediction model. Additionally, the degradation rate achieved in this study was higher than that by Geobacillus kaustophilus TERINSM (Sood and Lal, 2008). These results indicate that strain PW1 is a good candidate that can be selected for application in oil wells that have paraffin deposition problems in order to enhance oil recovery. This strain will be tested in actual oil wells shortly.

$\mathbf{A}$

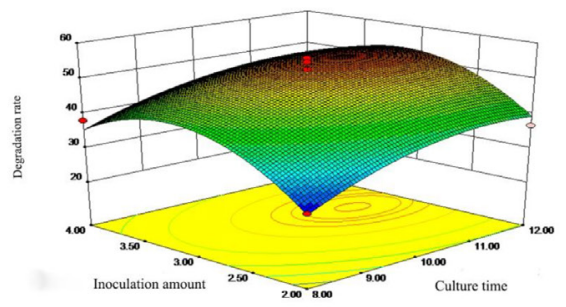

B

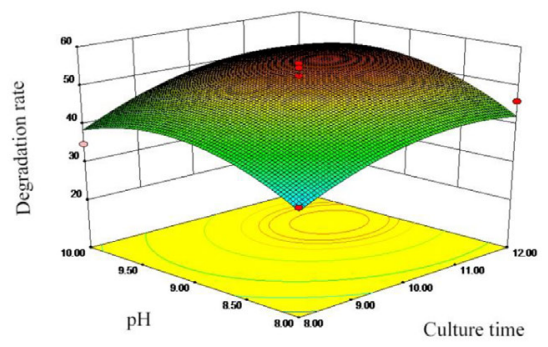

C

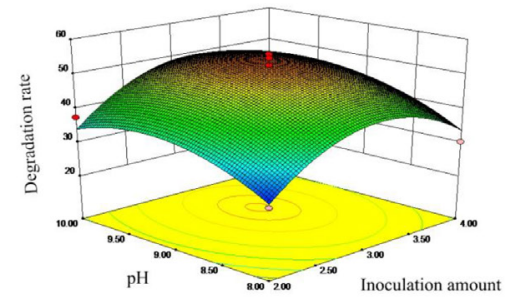

Figure 4. Contour plot of the effect of the culture time, inoculation amount, and $\mathrm{pH}$ on the degradation of paraffin wax by Pseudomonas sp strain PW-1. A. Contour plot of the effect of the culture time and inoculation amount on the degradation of paraffin wax by P. seudomonas sp strain PW-1. B. Contour plot of the effect of the culture time and $\mathrm{pH}$ on the degradation of paraffin wax by Pseudomonas sp strain PW-1. C. Contour plot of the effect of the $\mathrm{pH}$ and inoculation amount on the degradation of paraffin wax by Pseudomonas sp strain PW-1. 


\section{Conflicts of interest}

The authors declare no conflicts of interest.

\section{ACKNOWLEDGMENTS}

Research supported by the NSFC (Grant \#31272026) and the Scientific Research Fund of Heilongjiang Provincial Education Department (\#11551327 and \#12511326).

\section{REFERENCES}

Araújo AEO, Mezzomo BP, Ferrari I and Grisolia CK (2010). Genotoxic effects caused by indoor exposure to petroleum derivatives in a fuel quality control laboratory. Genet. Mol. Res. 9: 1069-1073. http://dx.doi.org/10.4238/vol92 gmr797

Atlas RM (1975). Effects of temperature and crude oil composition on petroleum biodegradation. Appl. Microbiol. 30: 396-403.

Azevedo LF and Texeira AM (2003). A critical review of the modeling of wax deposition mechanisms. Petrol. Sci. Technol. 21: 393-408. http://dx.doi.org/10.1081/LFT-120018528

Barker KM, Newberry ME and Yin YR (2001). Paraffin solvation in the oil field. Soc. Petrol. Eng. J. 64995

Bott TR (1997). Aspects of crystallization fouling. Exp. Therm. Fluid Sci. 14: 356-360. http://dx.doi.org/10.1016/S0894$\underline{1777(96) 00137-9}$

Brown TS, Niesen VG and Eerickson DD (1993). Measurement and prediction of the kinetics of paraffin deposition. Soc. Petrol. Eng. 26548.

Buehanan RE and Gibbons NE (1974). In: Bergey's Manual of Determinative Bacteriology. 8th edn. The Williams \& Wilkins company, Baltimore, 529-545.

Burguer ED, Perkins TK and Striegler JH (1981). Studies of wax deposition in the Trans Alaska Pipeline. J. Pet. Technol. 33: 1075-1086. http://dx.doi.org/10.2118/8788-PA

Das N and Chandran P (2011). Microbial degradation of petroleum hydrocarbon contaminants: an overview. Biotechnol. Res. Int. 2011: 941810. http://dx.doi.org/10.4061/2011/941810

Ferrara GB, Murgia B, Parodi AM, Valisano L, et al. (2006). The assessment of DNA from marine organisms via a modified salting-out protocol. Cell. Mol. Biol. Lett. 11: 155-160. http://dx.doi.org/10.2478/s11658-006-0013-7

Guerra-Santos L, Käppeli O and Fiechter A (1984). Pseudomonas aeruginosa biosurfactant production in continuous culture with glucose as carbon source. Appl. Environ. Microbiol. 48: 301-305.

Hasanuzzaman M, Ueno A, Ito $\mathrm{H}$, Ito $\mathrm{Y}$, et al. (2007). Degradation of long-chain n-alkanes $\left(\mathrm{C}_{36}\right.$ and $\left.\mathrm{C}_{40}\right)$ by Pseudomonas aeruginosa strain WatG. Int. Biodeter. Biodegr 59: 40-43. http://dx.doi.org/10.1016/j.ibiod.2006.07.010

Huang QY, Wang JF and Zhang JJ (2009). Physical properties of wax deposits on the walls of crude pipelines. Petrol. Sci 6: 64-68. http://dx.doi.org/10.1007/s12182-009-0011-2

Huang XF, Guan W, Liu J, Lu LJ, et al. (2010). Characterization and phylogenetic analysis of biodemulsifier-producing bacteria. Bioresour. Technol. 101: 317-323. http://dx.doi.org/10.1016/j.biortech.2009.07.086

Khalil CN, Rocha NO and Silva EB (1997). Detection of Formation Damage Associated to Paraffin in Reservoirs of the Recôncavo Baiano. Presented at the International Symposium on Oilfield Chemistry, Houston, 18-21.

Koma D, Hasumi F, Yamamoto E, Ohta T, et al. (2001). Biodegradation of long-chain n-paraffins from waste oil of car engine by Acinetobacter sp. J. Biosci. Bioeng. 91: 94-96. http://dx.doi.org/10.1016/S1389-1723(01)80120-1

Kotlar HK, Wentzel A, Throne-holst M, Zotchev S, et al. (2007). Wax control by biocatalytic degradation in high paraffinic crude oils. Soc. Petrol. Eng. J. 106420-MS. doi: 10.2118/106420-MS.

Leorpz AT (2004). Study of Wax Deposition in Petroleum Pipelines. Doctoral thesis, Pontifícia Universidade Católica de Rio de Janeiro, Brazil.

Liu T, Hou JM, Bi SN, Zuo YH, et al. (2011). Isolation and characterization of a biosurfactant-producing bacterium from Daqing oil-contaminated sites. Afr. J. Microbiol. Res. 5: 3509-3514.

Moreira IS, Amorim CL, Carvalho MF and Castro PM (2012). Degradation of difluorobenzenes by the wild strain Labrys portucalensis. Biodegradation 23: 653-662. http://dx.doi.org/10.1007/s10532-012-9541-1

Moreira IS, Amorim CL, Carvalho MF, Ferreira AC, et al. (2013). Effect of the metals iron, copper and silver on fluorobenzene biodegradation by Labrys portucalensis. Biodegradation 24: 245-255. http://dx.doi.org/10.1007/ 
$\underline{\mathrm{s} 10532-012-9581-6}$

Obayori OS, Ilori MO, Adebusoye SA, Oyetibo GO, et al. (2008). Pyrene-degradation potentials of Pseudomonas species isolated from polluted tropical soils. World J. Microbiol. Biotechnol. 24: 2639-2646. http://dx.doi.org/10.1007/ $\underline{\text { s11274-008-9790-7 }}$

Sood $\mathrm{N}$ and Lal B (2008). Isolation and characterization of a potential paraffin-wax degrading thermophilic bacterial strain Geobacillus kaustophilus TERI NSM for application in oil wells with paraffin deposition problems. Chemosphere 70: 1445-1451. http://dx.doi.org/10.1016/j.chemosphere.2007.08.071

Tani A, Ishige T, Sakai Y and Kato N (2001). Gene structures and regulation of the alkane hydroxylase complex in Acinetobacter sp. strain M-1. J. Bacteriol. 183: 1819-1823. http://dx.doi.org/10.1128/JB.183.5.1819-1823.2001

van Beilen JB, Panke S, Lucchini S, Franchini AG, et al. (2001). Analysis of Pseudomonas putida alkane-degradation gene clusters and flanking insertion sequences: evolution and regulation of the alk genes. Microbiology 147: 1621-1630. http://dx.doi.org/10.1099/00221287-147-6-1621

Yalcin E, Cavusoglu K and Ozen E (2011). Hydrocarbon degradation by a new Pseudomonas, strain RW- with polycationic surfactant to modify the cell hydrophobicity. Environ. Technol. 33: 1743-1747.

Zhuang WJ (2008). Isolation of diesel oil degradation bacteria, optimize of degradation condition and the research on its degradable mechanism. Master's thesis, Hunan University, China.

\section{Supplementary material}

S1 Table. Physiological and biochemical characteristics of the isolate PW-1.

S2 Table. Test factors and level of response surface experiments.

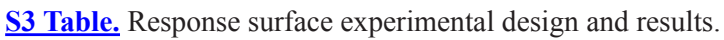

$\underline{\text { S4 Table. }}$ Central composite design regression coefficients and significant test results. 